\title{
Extraction, Identification and Antioxidative Properties of the Flavonoid-Rich Fractions from Leaves and Flowers of Cassia angustifolia
}

\author{
Abdul Qayoom Laghari ${ }^{1}$, Shahabuddin Memon ${ }^{1 *}$, Aisha Nelofar ${ }^{2}$, Abdul Hafeez Laghari ${ }^{1,2}$ \\ ${ }^{1}$ National Center of Excellence in Analytical Chemistry, University of Sindh, Jamshoro, Pakistan \\ ${ }^{2}$ Pakistan Council of Scientific and Industrial Research, Karachi, Pakistan \\ E-mail: *shahabuddinmemon@yahoo.com \\ Received August 17, 2011; revised September 26, 2011; accepted October 9, 2011
}

\begin{abstract}
Flavonoids identification, total flavonoids content and antioxidant activity of the extracts from the leaves as well as flowers of Cassia angustifolia were determined. Five different extraction techniques were used for the extraction of flavonoids from leaves and flowers. Total flavonoid contents (TFC) in the extracts were determined by UV-visible spectrophotometry. Individual flavonoids were identified and quantified by high-performance liquid chromatography coupled with photodiode array detection and electrospray ionization tandem mass spectrometry (HPLC-PDA-ESI-MS). It has been examined that aqueous ethanol (70\%) fractions of $C$. angustifolia flowers and leaves are highly rich in flavonoids and microwave extraction is the best method for the extraction of individual flavanoid constituents $(1-9)$ as well as total flavonoid contents. It was also found that compound 8 was absent in the leaves and compounds 2 and 5 could not be identified. The extracts of $C$. angustifolia flowers and leaves show strong antioxidant activity.
\end{abstract}

Keywords: Cassia angustifolia, Flavonoids, Antioxidant Activity, HPLC-ESI-MS, Microwave Extraction

\section{Introduction}

Flavonoids are the polyphenolic phytochemicals with inconsistent phenolic structures; they consist of flavones, flavanone, flavanols, flavonols and flavanonols that comprise a large group of secondary metabolites in plants [1-4]. They are found in vegetables, fruits, flowers, grains, barks, roots and stems [5]. Flavonoids have significant biological activities, such as anti-microbial [6], antioxidant [7], anti-cancer [8] and anti-inflammatory activity [9]. Present study was carried out to investigate flavonoids in the Cassia angustifolia due to its significance in curing different diseases.

Cassia angustifolia Vahl. (Caesalpiniaceae) commonly known as Sanna makkai, grows in hot arid areas of Pakistan and India. It's a reputed drug in traditional medicine and frequently used in folk medicine as a purgative for a long time [10]. Most of pharmacopoeias of the world have also recorded this plant [11]. Due to its cathartic properties it is valued as a medicine and is particularly useful in habitual constipation. It is employed in the treatment of amoebic dysentery as an anthelmintic and as a mild liver stimulant [12]. It is extensively used as febrifuge in splenic enlargements, typhoid, cholera, anemia [13], laxative, genotoxicity, and toxicity in Escherichia coli [14]. Leaves and pods of $C$. angustifolia are traditionally used as purgatives; the most important purgative constituents are Sennosides A, B, C, D, emodin, isorhamnetin and essential oil [15]. Leaves of $C$. angustifolia are also used as a safe laxative and this plant contributes considerably to commercial drugs and has been investigated in several parts of the world for various therapeutic preparations in different ways [16].

Due to enormous usage of $C$. angustifolia in curing different diseases and the work reported in the literature concerning systemic study of chemical composition encouraged to further explore its active constituents responsible for bioactivity. In present study extraction of flavonoids from the leaves and flowers of C. angustifolia, has been done by using five different extraction techniques. Identification of flavonoids, total flavonoid contents and antioxidant activity of the different extracts was also determined. 


\section{Experimental}

\subsection{General}

Formic acid, sodium nitrite, aluminum chloride, sodium hydroxide were purchased from Merck Schuchardt $\mathrm{OHG}$ 85662 (Hohenbrunn, Germany). Butylated hydroxyanisole (BHA) was procured from BDH laboratory reagents (Poole England). Acetonitrile, methanol, ethanol and petroleum ether (40 - $60 \mathrm{Bp}$ ) (HPLC grade) were purchased from Lab-Scan Analytical Science (Bankok 10330 Thailand).

\subsection{Plant Material}

The leaves and flowers of $C$. angustifolia were collected in March 2010 from Nangar parkar district Mithi at Tharparkar of Sindh province, Pakistan. Plant has been identified by Dr. Abdul Jabbar Pirzada, Assistant Professor, Institute of Plant Sciences, University of Sindh, Jamshoro/Pakistan.

\subsection{Extraction of Flavonoids}

Fatty constituents from the leaves or flowers (coarsely powdered and shade dried) were extracted with petroleum ether by soxhlet extraction. About one and half hour was taken to extract all fatty constituents and solvent became colorless when left for further extraction. Then flavonoids extraction from defatted plant material was performed by a reported method [17] with slight modification.

\subsubsection{Microwave Extraction}

$1 \mathrm{~g}$ of defatted flowers or leaves were taken in vessel already containing $50 \mathrm{~mL}$ of aqueous ethanol (70\%), then the vessel was placed into microwave decomposition system (Start E Microwave Extraction system, Mile stone, Model-Act 38-Revol-03106) for microwave-assisted extraction. The temperature for extraction was $50^{\circ} \mathrm{C}$ and time for extraction was $9 \mathrm{~min}$. After this the sample was filtered and volume was made $50 \mathrm{~mL}$ in a volumetric flask with aqueous ethanol (70\%) solvent.

\subsubsection{Soxhlet Extraction}

$1 \mathrm{~g}$ of defatted flowers or leaves were taken and shifted into filter paper thimble. $160 \mathrm{~mL}$ of aqueous ethanol $(70 \%)$ were poured into round bottom flask $(250 \mathrm{~mL}$ capacity) followed by fitting it on soxhlet assembly on water bath. Extraction time was $5 \mathrm{~h}$, until the clear solution was observed in Soxhlet, where thimble was placed. Solvent was then evaporated under vacuum and the extract was diluted with same solvent and volume was made $50 \mathrm{~mL}$ in volumetric flask.

\subsubsection{Sonication Extraction}

$1 \mathrm{~g}$ of defatted flowers or leaves were taken and shifted into a conical flask ( $100 \mathrm{~mL}$ capacity) containing $50 \mathrm{~mL}$ of aqueous ethanol $(70 \%)$. It was sonicated in ultrasonic bath (Supersonic X-3, Model DSD80A5QS) for one hour. It was then filtered and volume was made up to $50 \mathrm{~mL}$ in volumetric flask in the same solvent.

\subsubsection{Marinated Extraction}

$1 \mathrm{~g}$ of defatted flowers or leaves were taken and shifted into conical flask ( $100 \mathrm{~mL}$ capacity) containing $50 \mathrm{~mL}$ of aqueous ethanol $(70 \%)$. It was left for $48 \mathrm{~h}$ at room temperature and filtered followed by dilution to make the volume up to $50 \mathrm{~mL}$ in a volumetric flask.

\subsubsection{Reflux Condensation Extraction}

$1 \mathrm{~g}$ of defatted flowers or leaves were taken and shifted into round bottom flask ( $100 \mathrm{~mL}$ capacity) containing 50 $\mathrm{mL}$ aqueous ethanol (70\%). After fixing a condenser, it was left for reflux condensation on heating mantel (Isopad LG2/ER $100 \mathrm{~mL}$, model 913323, Tmax-450 ${ }^{\circ} \mathrm{C}$ ) for two and half hours. Extract was filtered and diluted up to $50 \mathrm{~mL}$.

\subsection{Determination of Total Flavonoid Contents}

Total flavonoid contents were determined by a reported method [17] with slight modification. The reaction mixture was comprised of $2 \mathrm{~mL}$ plant extracts, $0.6 \mathrm{~mL}$ sodium nitrite $(5 \% w / v), 0.5 \mathrm{~mL}$ of aluminum chloride $(10 \% \mathrm{w} / \mathrm{v}), 3 \mathrm{~mL}$ of sodium hydroxide $(4.3 \% \mathrm{w} / \mathrm{v})$ and distilled water to make volume $10 \mathrm{~mL}$. In each step, 6 min. time period was given for shaking to complete reaction. Afterward, the solution was allowed to stand for 15 min. before measuring the absorbance. Measurement of absorbance at $500 \mathrm{~nm}$ was performed on a Specord 200 analticjena UV-vis spectrophotometer (Germany), with a $1 \mathrm{~cm}$ cell. Aqueous ethanol (70\%) was used as reference, rutin was used as a standard and results were calculated as rutin equivalents (Rutin eq., $\mathrm{mg} / \mathrm{mL}$ ) of $C$. angustifolia.

\subsection{Chromatographic Analysis of Flavonoids}

The analysis of flavonoids in samples was carried out by using HPLC-ESI-MS/MS. The HPLC conditions adjusted were as follows:

The liquid chromatograph system was equipped with the photo diode array detector (PDA) and a vacuum degasser. Separations were made by using Hypersil Gold C18 $(250 \mathrm{~mm} \times 4.6 \mathrm{~mm}, 5 \mu \mathrm{m})$ (Thermo electron corpo- 
ration USA) column and analytical data was evaluated by using X-Caliber data processing system (2.0 SR2). The mobile phase was composed of methanol-acetonitrile $(7: 3)(\mathrm{A})$ and $0.1 \%, v / v$ formic acid in water (B). The flow rate was $1 \mathrm{~mL} / \mathrm{min}$. The gradient programming was as follows; starting from concentration of A at 5\% for 5 minutes and then gradual increase from $5 \%$ to $30 \%$ in 10 minutes. Isocratic step of 5 minutes and then brought back to $5 \%$ in $5 \mathrm{~min}$ followed by $5 \mathrm{~min}$ for column equilibration. The eluent was monitored using the PDA detector set at three different wavelengths 270, 320 and $360 \mathrm{~nm}$.

\subsection{Identification and Qualitative Analysis of Constituents by LC-MS}

Identification of the constituents was performed with a Thermo Finnigan LCQ Advantage ion trap mass spec- trometer (Vernon Hills, Illinois, USA) fitted with the liquid chromatograph system coupled on-line with an Electro Spray Ionization (ESI) source and X-Caliber software was used for data acquisition. Analytical conditions were: positive ion mass spectra of the column elute were recorded in the range $\mathrm{m} / \mathrm{z} 200-700$. Capillary temperature was kept at $200^{\circ} \mathrm{C}$ and Voltage $4.5 \mathrm{kV}$. Sheath gas flow rate was kept at 70 (arbitrary unit). The resulting total ion chromatogram (Figures 1(a)-(b)) is a plot of time $v s$ area showing the total response of each constituent on the basis of its molecular ion abundance. Identification of individual flavonoids in extracts was carried out with the help of LC-MS-ESI by comparing their masses and $\lambda_{\max }$ with the literature data [18-24].

\subsection{DPPH Antioxidant Activity}

DPPH scavenging ability of $C$. angustifolia flowers or

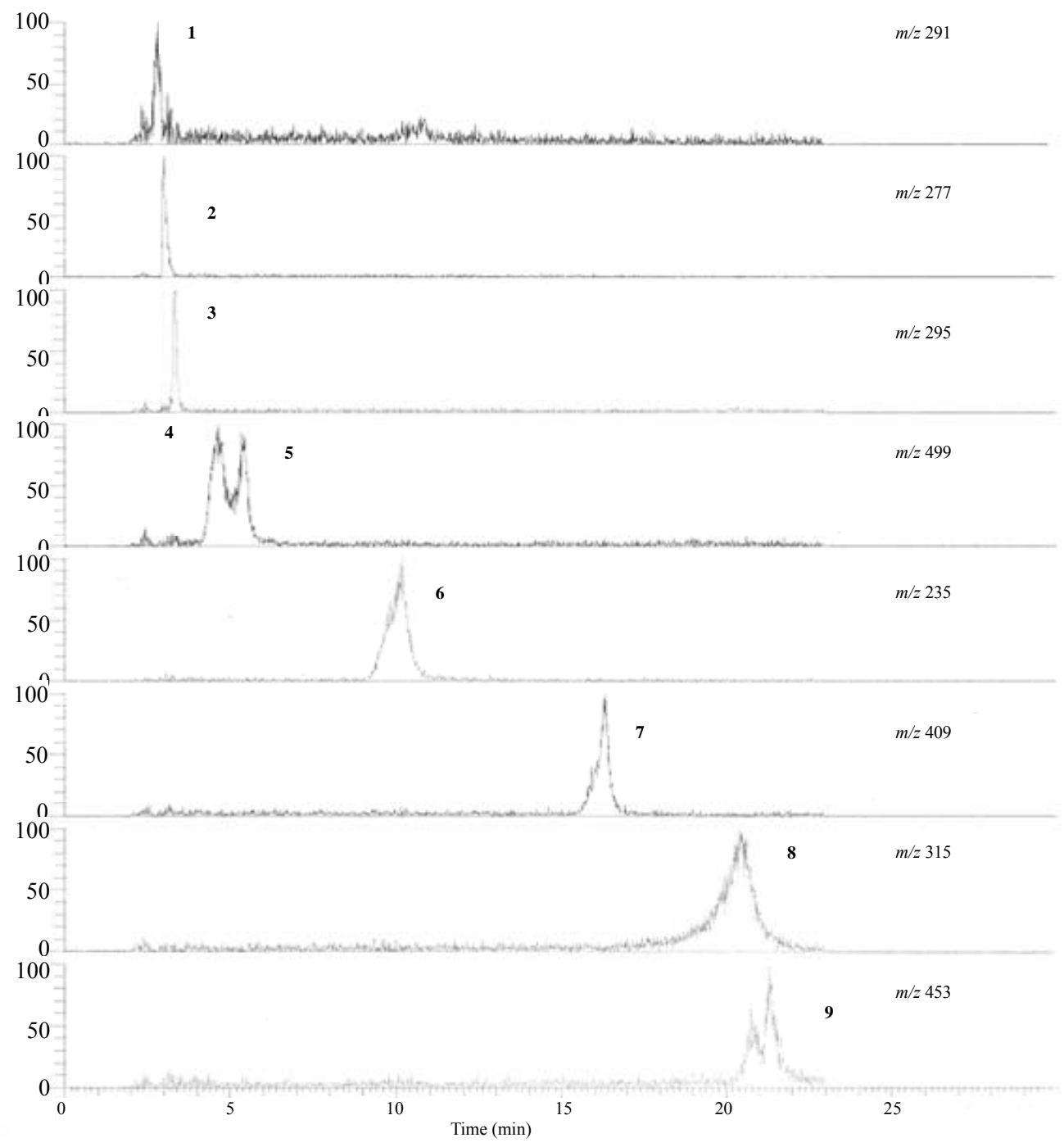

(a) 


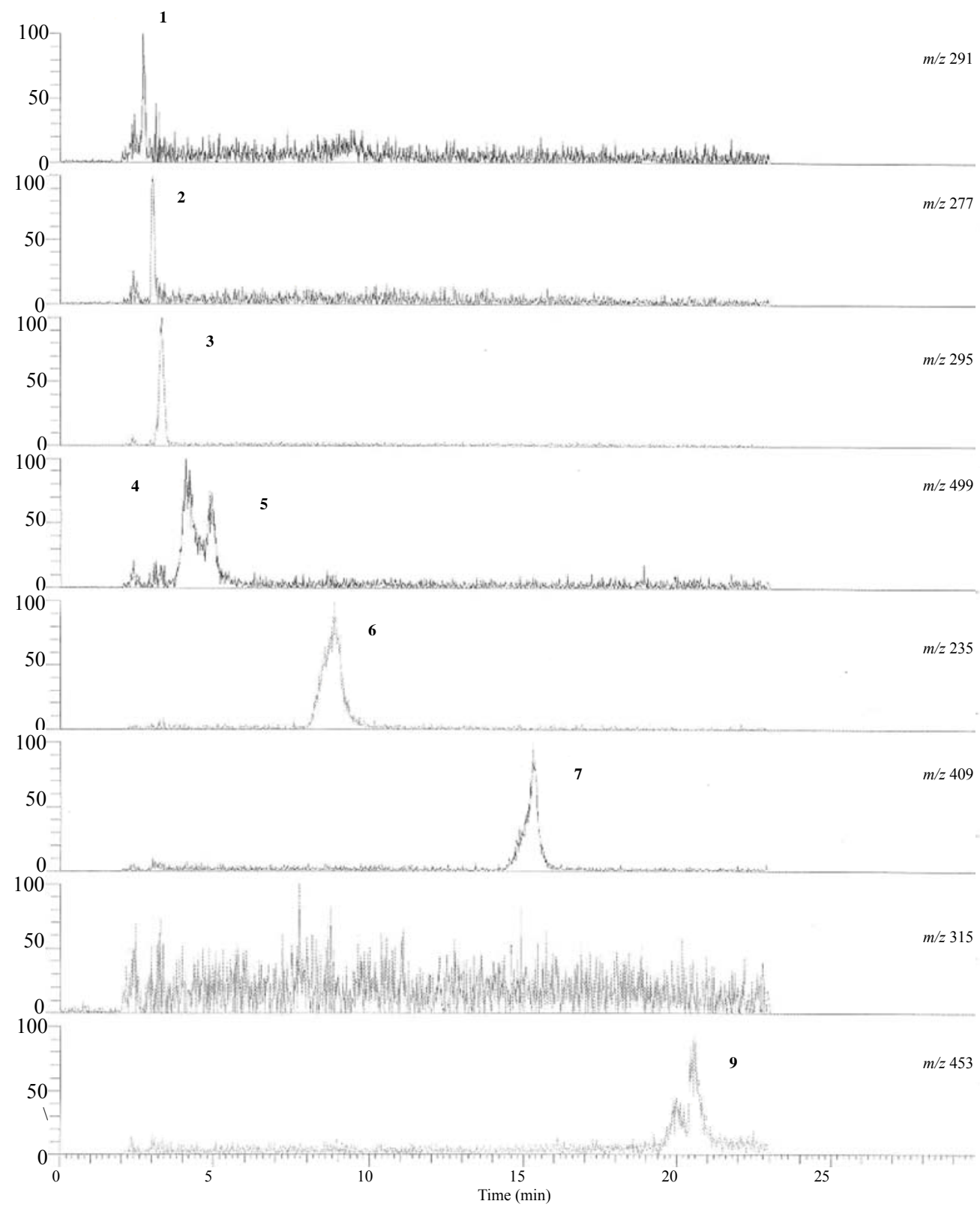

(b)

Figure 1. HPLC-MS chromatogram of the compounds identified from flowers (a) and leaves (b).

leaves extracts was measured by their bleaching capability toward purple DPPH methanol solution. This assay was performed according to the reported method $[25,26]$ by mixing $3 \mathrm{ml}$ of $0.1 \mathrm{mM}$ DPPH in methanol and $1 \mathrm{ml}$ of sample solution in aqueous ethanol (70\%). The absorbance was measured on Specord 200 analticjena UV-vis spectrophotometer (Germany) at $517 \mathrm{~nm}$. Decreasing amplitude of signal at the selected wavelength confirmed a high radical scavenging activity. In addition, the antioxidant activity of BHA as standard reference was assayed; methanol was used as blank and the meas- urement of solutions without sample were used as the control. The inhibition of DPPH radicals by the samples was calculated as follows:

$$
\text { DPPH inhibition }(\%)=[(\mathrm{A}-\mathrm{B}) / \mathrm{A}] \times 100 \text {. }
$$

where $\mathrm{A}$ is the absorbance without extract and $\mathrm{B}$ is the absorbance with the extract.

$\mathrm{IC}_{50}$ values were calculated by considering the $50 \%$ inhibition of DPPH free radical in $5 \mathrm{~min}$ by flowers or leaves samples at minimum concentration and comparing with same response shown by BHA. 


\section{Results and Discussion}

\subsection{Identification and Quantification of Flavonoids}

Identification of the individual flavonoids was performed through HPLC-PDA-ESI/MS, by comparing their masses and $\lambda_{\max }$ with the literature data (Table 1) [18-24]. Epicatechin (1), (-)-(2S)-6-Methoxy-[2",3":7,8]-furanoflavanone (3), Kaempferol 3-O-sulphate-7-O-c-arabi- nopyranoside (4), Vidalenolone (6), (2S)-7,8, bis-3',4'(2,2-dimethyl-chromano)-5-hydroxyflavanone (7), 3,7dihydroxy-4',8-dimethoxyflavone (8) and 14-hydroxyartonin $E$ (9) were indentified, but compounds $\mathbf{2}$ and $\mathbf{5}$ could not be identified, because the data does not match with the literature, may be these compounds are new and first time reported. Chemical structures of the identified compounds are given in Figure 2; it shows that from seven identified compounds, $\mathbf{3}$ and $\mathbf{7}$ are flavanones, remaining are flavones except compound $\mathbf{6}$, which is not a flavonoid but a phenolic metabolite, i.e. Vidalenolone. All of these are free flavonoids except compound $\mathbf{4}$ which contains arabinopyranoside moiety.

Flowers of $C$. angustifolia contains all 1-9 compounds in varying quantities, on the other hand compound $\mathbf{8}$ was absent in leaves. Microwave and soxhlet extraction techniques are the best techniques to extract all 1-9 compounds from the flowers and leaves, with exception of compound $\mathbf{8}$, which was not found may be it is absent in the leaves. While the compound $\mathbf{6}$ and $\mathbf{8}$ could not be extracted by other extraction techniques like sonication, marination and reflux condensation. Flowers contain greater amount of total flavonoids than the leaves.

Quantification was performed in relative $\%$ by taking area of all constituents from HPLC-MS chromatogram and taking it as denominator to calculate each constituent by putting area of that content in numerator and multiplying by 100 . It was found that the relative percentage of individual flavonoids varies in different extraction techniques (Table 2). Relative percentage composition of the compounds were higher in microwave extraction techniques with few exceptions, compound 6 was higher in soxhlet; both in flowers and leaves, while compound $\mathbf{1}$ and 5 were higher in reflux condensation extraction, but compound 5 was higher only in leaves.

\subsection{Total Flavonoid Contents}

Among all the other extraction methods the total flavonoid contents (Table 3) have been found higher in microwave extraction, i.e. $28.15 \mathrm{mg} / \mathrm{g}$ and $26.3 \mathrm{mg} / \mathrm{g}$ in the flowers and leaves, respectively. While lowest amount of total flavonoid contents were found in case of flowers and leaves extracts obtained by reflux condensation and sonication extraction methods, respectively. As a result, it could be suggested that microwave extraction technique is best option to extract flavonoids in higher amounts.

\subsection{Advantages and Disadvantages of the Extraction Methods}

Five different extraction techniques were used and extraction efficiency was found to be dependent on all the techniques. The purpose of using five different techniques is to find out a convenient extraction method in order to obtain more number and greater quantity of flavonoids. However, microwave extraction method has been found as the best option for the extraction of flavonoids; it's very easy, robust and least time consuming

Table 1. Flavonoid glycosides identified from the extracts of leaves and flowers by HPLC-PDA-ESI/MS.

\begin{tabular}{|c|c|c|c|c|c|c|}
\hline \multirow{2}{*}{ S. No. } & \multirow{2}{*}{ Identity } & \multirow{2}{*}{$\begin{array}{l}\lambda_{\max }(n m) \\
\text { Reported }\end{array}$} & \multirow{2}{*}{$\begin{array}{l}\lambda_{\max }(n m) \\
\text { Samples }\end{array}$} & \multirow{2}{*}{$\begin{array}{c}\text { Calculated } \\
\text { molecular } \\
\text { mass }\end{array}$} & \multicolumn{2}{|c|}{$\begin{array}{c}\text { Found } \\
\text { in samples }\end{array}$} \\
\hline & & & & & $\mathrm{M}+1$ & $\mathrm{MS}^{2}$ \\
\hline 1 & Epicatechin & 225,267 & 224,269 & 290 & 291 & 273 \\
\hline 2 & unknown & - & 232,264 & 276 & 277 & - \\
\hline 3 & (-)-(2S)-6-Methoxy-[2",3":7,8]-furanoflavanone & $234,247,341$ & $233,253,338$ & 294 & 295 & 190 \\
\hline 4 & Kaempferol 3-O-sulphate-7-O-c-arabinopyranoside & 270,350 & 272,345 & 498 & 499 & 287 \\
\hline 5 & unknown & - & $230,274,320$ & 498 & 499 & - \\
\hline 6 & Vidalenolone & 224,266 & 225,267 & 234 & 235 & 203 \\
\hline 7 & $\begin{array}{c}(2 S)-7,8, \text { bis-3',4'-(2,2-dimethyl-chromano)-5-hydro } \\
\text { xyflavanone }\end{array}$ & $217,294,340$ & $220,292,340$ & 408 & 409 & 221 \\
\hline 8 & 3,7-dihydroxy-4',8-dimethoxyflavone & 250,304 & 249,306 & 314 & 315 & 300 \\
\hline 9 & 14-Hydroxyartonin $E$ & $270,314,387$ & $269,315,387$ & 452 & 453 & 435 \\
\hline
\end{tabular}


<smiles>O=C1c2c(O)cc(O)cc2OC(c2ccc(O)c(O)c2)C1O</smiles>

Epicatechin (1)<smiles>COc1cc2c(c3ccoc13)OC(c1ccccc1)CC2=O</smiles>

(-)-(2S)-6-Methoxy-[2",3”:7,8]-furanoflavanone (3)<smiles></smiles>

Kaempferol 3-O-sulphate-7-O-c-arabinopyranoside (4)<smiles>COC1(Cc2ccc(O)cc2)CC=C(O)C1=O</smiles>

Vidalenolone (6)<smiles>CC1(C)CCc2cc(C3CC(=O)c4ccc5c(c4O3)CCC(C)(C)O5)ccc2O1</smiles>

(2S)-7,8,bis-3',4'-(2,2-dimethyl-chromano)-5-hydroxyflavanone (7)<smiles>COc1ccc(-c2oc3c(OC)c(O)ccc3c(=O)c2O)cc1</smiles>

3,7-dihydroxy-4',8-dimethoxyflavone (8)<smiles>C/C(=C\Cc1c(-c2cc(O)c(O)cc2O)oc2c3c(cc(O)c2c1=O)OC(C)(C)C=C3)CO</smiles>

14-Hydroxyartonin $E$ (9)

Figure 2. Chemical structures of flavonoids and phenolic compounds (1-9) identified from the flowers and leaves.

Table 2. Relative amount of each flavonoid in samples with different extraction techniques.

\begin{tabular}{|c|c|c|c|c|c|c|c|c|c|c|}
\hline \multirow{3}{*}{ Compound } & \multicolumn{10}{|c|}{ Extraction techniques } \\
\hline & \multicolumn{2}{|c|}{ Microwave } & \multicolumn{2}{|c|}{ Soxhlet } & \multicolumn{2}{|c|}{ Marination } & \multicolumn{2}{|c|}{ Sonication } & \multicolumn{2}{|c|}{ Reflux } \\
\hline & Flowers & Leaves & Flowers & Leaves & Flowers & Leaves & Flowers & Leaves & Flowers & Leaves \\
\hline 1 & 20.3 & 24.2 & 18.0 & 16.2 & 21.5 & 16.9 & 18.7 & 17.1 & 21.5 & 25.6 \\
\hline 2 & 36.9 & 30.8 & 18.1 & 16.3 & 16.0 & 17.0 & 15.4 & 19.2 & 13.5 & 16.7 \\
\hline 4 & 28.5 & 20.4 & 17.6 & 17.8 & 16.9 & 21.8 & 16.2 & 16.8 & 20.7 & 23.2 \\
\hline 5 & 21.5 & 20.3 & 19.3 & 16.9 & 18.3 & 20.6 & 20.0 & 16.6 & 20.8 & 25.7 \\
\hline 6 & 49.2 & 46.9 & 50.8 & 53.1 & - & - & - & - & - & - \\
\hline 7 & 28.2 & 25.2 & 18.0 & 22.8 & 18.7 & 18.6 & 17.3 & 16.7 & 17.8 & 16.5 \\
\hline 8 & 52.7 & - & 47.3 & - & - & - & - & - & - & - \\
\hline
\end{tabular}

All values are in relative $\%$.

Table 3. Total flavonoids content in the leaves and flowers and comparison in the extraction methods.

\begin{tabular}{cccc}
\hline S.NO & Extraction methods & $\begin{array}{c}\text { Total flavonoids contents in flowers } \\
(\mathrm{mg} / \mathrm{g})\end{array}$ & $\begin{array}{c}\text { Total flavonoids contents in leaves } \\
(\mathrm{mg} / \mathrm{g})\end{array}$ \\
\hline 1 & Microwave extraction & 28.15 & 26.30 \\
2 & Soxhlet extraction & 27.35 & 22.52 \\
3 & Sonication & 20.64 & 16.41 \\
4 & Marinated extraction & 22.38 & 20.83 \\
5 & Reflux extraction & 18.07 & 19.91 \\
\hline
\end{tabular}


method and found to be the more efficient for extracting more number of flavonoids in higher quantity and also extracts obtained by this method show higher antioxidant activity. On the other hand the rest of the methods were very difficult more time consuming and their flavonoids extraction efficiency was also low as compared to microwave extraction method. These comparative results are tabulated in Tables 2-4.

\subsection{Assay of DPPH}

C. angustifolia flowers or leaves extracts show highest DPPH scavenging ability than the reference BHA standard (Table 4). Among all extraction techniques, it was found that microwave extracts show highest antioxidant activity than rest of the extracts obtained by other techniques. Flowers show high antioxidant activity as compared to leaves. Only $11 \%$ of the extract was enough to exhibit 50\% DPPH with reference to BHA in the same time. Thus, it can be assumed that the contribution to antioxidant ability of $C$. angustifolia extracts is mainly due to the presence of all identified flavonoids, which were extracted in highest quantity by microwave extraction.

\section{Conclusions}

Determination of flavonoids and antioxidative property of $C$. angustifolia were made in present study. Different extraction methods were used to extract the flavonoids and to find out the best one by comparing their efficiency and robustness. Among all these methods; microwave extraction was found to be the best method for extraction of flavonoids. All extracts show noticeable antioxidant activity. The importance of $C$. angustifolia with these properties, i.e. high antioxidant activity, total flavonoids content and presence of identified compounds (1-9) make it an eager and better alternative to the synthetic antioxidant agents and flavonoid sources. The compounds $\mathbf{2}$ and 5 have not been identified because their data do not match with reported literature; may be these are new and in future studies their isolation, identification and biological activities will be carried out. All the identified flavonoids are first time reported from this plant, this data may be useful for the isolation of the targeted identified flavonoids. The compound $\mathbf{6}$ is not a flavonoid, but it is identified as Vidalenolone; a phenolic metabolite. Hence, the present study may be helpful to pharmaceutical industry as well as to folk medication practitioners, who use this plant as a source of curing diseases.

\section{Acknowledgements}

Financial support during the present study made by the
Table 4. DPPH \% inhibition activity of the extracts of flowers (a), leaves (b) and reference.

\begin{tabular}{cccc}
\hline S.NO & Compound/Sample & ${ }^{*} 1 \mathrm{C}_{50}(\mathrm{a})$ & ${ }^{*} 1 \mathrm{C}_{50}(\mathrm{~b})$ \\
\hline 1 & BHA & $347.2 \mu \mathrm{M}$ & $347.2 \mu \mathrm{M}$ \\
2 & Microwave & $3.1 \mathrm{mg} / \mathrm{L}$ & $3.6 \mathrm{mg} / \mathrm{L}$ \\
3 & Soxhlet & $3.4 \mathrm{mg} / \mathrm{L}$ & $4.2 \mathrm{mg} / \mathrm{L}$ \\
4 & Sonication & $5.9 \mathrm{mg} / \mathrm{L}$ & $7.4 \mathrm{mg} / \mathrm{L}$ \\
5 & Marinated & $3.5 \mathrm{mg} / \mathrm{L}$ & $5.6 \mathrm{mg} / \mathrm{L}$ \\
6 & Reflux & $6.5 \mathrm{mg} / \mathrm{L}$ & $6.2 \mathrm{mg} / \mathrm{L}$ \\
\hline
\end{tabular}

* Concentration (in moles) at which $50 \%$ inhibition of DPPH is observed by reference; ${ }^{*}$ Concentration $(\mathrm{mg} / \mathrm{L})$ at which $50 \%$ inhibition of DPPH is observed by samples in the same time period by the reference.

National Centre of Excellence in Analytical Chemistry, University of Sindh, Jamshoro/Pakistan and Pakistan Council of Scientific and Industrial Research, Karachi/Pakistan is gratefully acknowledged.

\section{References}

[1] S. Hamamatsu, K. Yabe and Y. Nawa, "Compositions of Anthocyanin and Other Flavonoids in Cultured Rabbiteye Blueberry (Vaccinium ashei Reade cv. Tiiblue)," Food Science and Technology Research, Vol. 10, No. 3, 2004, pp. 239-246. doi:10.3136/fstr.10.239

[2] M. D. R. Santos, A. P. Vitor, J. C. Carneiro, D. S. C. Paciullo, R. C. Matos and M. A. C. Matos, "Use of Ultrasound Bath in the Extraction and Quantification of Ester-Linked Phenolic Acids in Tropical Forages," American Journal of Analytical Chemistry, Vol. 2, No. 3, 2011, pp. 344-351. doi:10.4236/ajac.2011.23042

[3] L. S. Chua, N. A. Latiff, S. Y. Lee, C. T. Lee, M. R. Sarmidi and R. A. Aziz, "Flavonoids and Phenolic Acids from Labisia pumila (Kacip Fatimah)," Food Chemistry, Vol. 127, No. 3, 2011, pp. 1186-1192. doi:10.1016/j.foodchem.2011.01.122

[4] A. H. Laghari, S. Memon, A. Nelofar, K. M. Khan, A. Yasmin, M. N. Syed and A. Aman, "A New Flavanenol with Urease-Inhibition Activity Isolated from Roots of Manna Plant Camelthorn (Alhagi maurorum)," Journal of Molecular Structure, Vol. 965, No. 1-3, 2010, pp. 65-67. doi:10.1016/j.molstruc.2009.11.039

[5] E. J. Middleton, "Effect of Plant Flavonoids on Immune and Inflammatory Cell Function," Advances in Experimental Medicine and Biology, Vol. 439, 1998, pp. 175-182. doi:10.1007/978-1-4615-5335-9 13

[6] T. P. Tim Cushnie and A. J. Lamb, "Antimicrobial Activeity of Flavonoids," International Journal of Antimicrobial Agents, Vol. 26, No. 5, 2005, pp. 343-356. doi:10.1016/j.ijantimicag.2005.09.002

[7] F. Shahidi and P. K. Wanasundara, "Phenolic Antioxidants," Critical Reviews in Food Science and Nutrition, Vol. 32, No. 1, 1992, pp. 67-103. 


\section{doi:10.1080/10408399209527581}

[8] H. Wei, L. Tye, E. Bresnick and D. F. Birt, "Inhibitory Effect of Epigenin, a Plant Flavonoid, on Epidermal Ornithine Decarboxylase and Skin Tumor Promotion in Mice," Cancer Research, Vol. 50, No. 3, 1990, pp. 499502.

[9] Y. Yamamoto and R. B. Gaynor, "Therapeutic Potential of Inhibition of the NFkB Pathway in the Treatment of Inflammation and Cancer," The Journal of Clinical Investigation, Vol. 107, No. 2, 2001, pp. 135-142. doi:10.1007/s10457-010-9316-9

[10] Q. P. Wu, Z. J. Wang, L. Y. Tang, M. H. Fu and Y. He, "A New Flavonoid Glucoside from Cassia angustifolia," Chinese Chemical Letters, Vol. 20, No. 3, 2009, pp. 320321. doi:10.1016/j.cclet.2008.12.003

[11] S. Hayashi, A. Yoshida, H. Tanaka, Y. Mitani and K. Yoshizawa, "Analytical Studies on the Active Constituents in Crude Drugs. IV. Determination of Sennosides in Senna and Formulations by High-Performance Liquid Chromatography," Chemical and Pharmaceutical Bulletin, Vol. 28, No. 2, 1980, pp. 406-412.

[12] I. Siddique, M. Anis and I. M. Aref, "In Vitro Adventitious Shoot Regeneration via Indirect Organogenesis from Petiole Explants of Cassia angustifolia Vahl.-A Potential Medicinal Plant," Applied Biochemistry and Biotechnology, Vol. 162, No. 7, 2010, pp. 2067-2074. doi:10.1007/s12010-010-8982-4

[13] S. Parveen and A. Shahzad, "A Micropropagation Protocol for Cassia angustifolia Vahl. from Root Explants," Acta Physiologiae Plantarum, Vol. 33, No. 3, 2011, pp. 789-796. doi:10.1007/s11738-010-0603-x

[14] C. R. Silva, M. R. Monteiro, H. M. Rocha, A. F. Ribeiro, A. Caldeira-de-Araujo, A. C. Leitão, R. J. A. C. Bezerra and M. Pádula, "Assessment of Antimutagenic and Genotoxic Potential of Senna (Cassia angustifolia Vahl.) Aqueous Extract Using in Vitro Assays," Toxicol in Vitro, Vol. 22, No. 1, 2008, pp. 212-218. doi:10.1016/j.tiv.2007.07.008

[15] I. Siddique and M. Anis, "In Vitro Shoot Multiplication and Plantlet Regeneration from Nodal Explants of Cassia angustifolia (Vahl.): A Medicinal Plant," Acta Physiologiae Plantarum, Vol. 29, No. 3, 2007, pp. 233-238. doi:10.1007/s11738-007-0029-2

[16] R. Arya, "Yield of Cassia angustifolia in Combination with Different Tree Species in a Silvi-Herbal Trial under Hot Arid Conditions in India," Bioresource Technology, Vol. 86, No. 2, 2003, pp. 165-169. doi:10.1016/S0960-8524(02)00150-5

[17] H. Zhu, Y. Wang, Y. Liu, Y. Xia and T. Tang, "Analysis of Flavonoids in Portulaca oleracea L. by UV-Vis Spectrophotometry with Comparative Study on Different Ex- traction Technologies," Food Analytical Methods, Vol. 3, No. 2, 2010, pp. 90-97. doi:10.1007/s12161-009-9091-2

[18] J. H. Lee, S. J. Lee, S. Park, H. K. Kim, W. Y. Jeong, J. Y. Choi, N.-J. Sung, W. S. Lee, C.-S. Lim, G.-S. Kim and S. C. Shin, "Characterisation of Flavonoids in Orostachys japonicus A. Berger Using HPLC-MS/MS: Contribution to the Overall Antioxidant Effect," Food Chemistry, Vol. 124, No. 4, 2011, pp. 1627-1633. doi:10.1016/j.foodchem.2010.08.031

[19] B. Sritularak, K. Likhitwitayawuid, J. Conrad and W. Kraus, "Flavonoids from the Roots of Millettia Erythrocalyx," Phytochemistry, Vol. 61, No. 8, 2002, pp. 943947. doi:10.1016/S0031-9422(02)00337-0

[20] W. Bylka, M. Stobiecki and R. Frański, "Sulphated Flavonoid Glycosides from Leaves of Atriplex hortensis," Acta Physiologiae Plantarum, Vol. 23, No. 3, 2001, pp. 285-290. doi:10.1007/s11738-001-0035-8

[21] H.-D. Yoo, S. O. Ketchum, D. France, K. Bair and W. H. Gerwick, "Vidalenolone, a Novel Phenolic Metabolite from the Tropical Red Alga Vidalia sp," Journal of $\mathrm{Na}$ tural Products, Vol. 65, No. 1, 2002, pp. 51-53. doi:10.1021/np010319c

[22] P.-L. Ding, A.-J. Hou and D.-F. Chen, "Three New Isoprenylated Flavonoids from the Roots of Sophora flavescens," Journal of Asian Natural Products Research, Vol. 7, No. 3, 2005, pp. 237-243. doi:10.1080/10286020410001687554

[23] M. A. Ponce, M. J. Bompadre, J. M. Scervino, J. A. Ocampo, E. J. Chaneton and A. M. Godeas, "Flavonoids, Benzoic Acids and Cinnamic Acids Isolated from Shoots and Roots of Italian Rye Grass (Lolium multiflorum Lam.) with and without Endophyte Association and Arbuscular Mycorrhizal Fungus," Biochemical Systematics and Ecology, Vol. 37, No. 4, 2009, pp. 245-253. doi:10.1016/j.bse.2009.03.010

[24] S. Cao, M. S. Butler and A. D. Buss, "Flavonoids from Artocarpus Lanceifolius," Natural Product Research, Vol. 17, No. 2, 2002, pp. 79-81. doi:10.1080/1478641031000103641

[25] L. Yu, M. Zhao, J. Wang, C. Cui, B. Yang, Y. Jiang and Q. Zhao, "Antioxidant, Immunomodulatory and AntiBreast Cancer Activities of Phenolic Extract from Pine (Pinus massoniana Lamb) Bark," Innovative Food Science and Emerging Technologies, Vol. 9, No. 1, 2008, pp. 122-128. doi:10.1016/j.ifset.2007.06.006

[26] A. H. Laghari, S. Memon, A. Nelofar, K. M. Khan and A. Yasmin, "Determination of Free Phenolic Acids and Anti-Oxidant Activity of Methanolic Extracts Obtained from Fruits and Leaves of Chenopodium album," Food Chemistry, Vol. 126, No. 4, 2011, pp. 1850-1855. doi:10.1016/j.foodchem.2010.11.165 